\title{
South African surgical registrar perceptions of the research project component of training: Hope for the future?
}

\author{
N Patel, ${ }^{1}$ BA Hons, MA, MB BCh; P Naidoo, ${ }^{2}$ BSc (Pharm Hons), MB BCh, MMedSc; M Smith, ${ }^{1}$ MB BCh, FCS (SA); \\ J Loveland, ${ }^{3} \mathrm{MB}$ BCh, FCS (SA), Cert Paed Surg; T Govender, ${ }^{1} \mathrm{MB}$ BCh; J Klopper, ${ }^{4} \mathrm{MB}$ BCh, FCS (SA \\ ${ }^{1}$ Department of Surgery, Faculty of Health Sciences, University of the Witwatersrand, Johannesburg, South Africa \\ ${ }^{2}$ Department of Internal Medicine, RK Khan Regional Hospital and School of Clinical Medicine, College of Health Sciences, \\ Nelson R Mandela School of Medicine, University of KwaZulu-Natal, Durban, South Africa \\ ${ }^{3}$ Department of Paediatric Surgery, Faculty of Health Sciences, University of the Witwatersrand, Johannesburg, South Africa \\ ${ }^{4}$ Department of Surgery, Faculty of Health Sciences, University of Cape Town, South Africa
}

Corresponding author: P Naidoo (poobalan1naidoo@yahoo.com)

\begin{abstract}
Background. The Health Professions Council of South Africa requires that a research project be submitted and passed before registration as a specialist.

Objective. To describe surgical registrars' perceptions of the compulsory research project.

Method. Ethics clearance was received before commencing the study. A questionnaire was developed to collect feedback from surgical registrars throughout South Africa (SA). Completed questionnaires underwent descriptive analysis using MS Excel. Fisher's exact test and the $\chi^{2}$ test were used to compare perceptions of the research-experienced and research-naive groups.

Results. All medical schools in SA were sampled, and 51.5\% (124/241) of surgical registrars completed the questionnaire. Challenges facing registrars included insufficient time (109/124), inadequate training in the research process (40/124), inadequate supervision (31/124), inadequate financial resources (25/124) and lack of research continuity (11/124). Of the registrars sampled, $67.7 \%(84 / 124)$ believed research to be a valuable component of training. An overwhelming percentage $(93.5 \%, 116 / 124)$ proposed a dedicated research block of time as a potential solution to overcoming the challenges encountered. Further proposals included attending a course in research methodology (79/124), supervision by a faculty member with an MMed or higher postgraduate degree (73/124), and greater research exposure as an undergraduate (56/124). No statistically significant differences were found between the perceptions of the researchexperienced and research-naive groups.

Conclusions. Challenges facing surgical registrars in their efforts to complete their research projects were identified and solutions to these problems proposed. It is heartening that respondents have suggested solutions to the problems they encounter, and view research as an important component of their careers.
\end{abstract}

S Afr Med J 2016;106(2):169-171. DOI:10.7196/SAMJ.2016.v106i2.10310

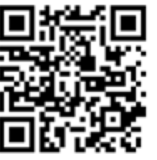

Postgraduate surgical training in South Africa (SA) consists of rotation as a registrar through various surgical disciplines, typically over a 4 -year period. Historically, subsequent to passing written and oral examinations and after completion of training rotation, the registrar has been registered as a specialist surgeon.

In 2010, the Health Professions Council of South Africa made it compulsory that a research project be submitted and passed before registration as a specialist. ${ }^{[1]}$ The research component of training, formalised in the research project, is viewed as a means of ensuring that future specialists are equipped with the basic analytical skills required to stay abreast with evidence-based advances in medicine. ${ }^{[2,3]}$ Published research gives universities opportunities to increase universities' research output, since all trainees are formally registered as postgraduate students, and also to receive state subsidy.

There is a paucity of local literature on the views of registrars regarding their completion of a research project. This study serves as an initial step in assessment of the needs of surgical registrars with regard to their conducting research.

\section{Methods}

Ethics clearance was obtained from the University of the Witwatersrand Research Ethics Committee. Data were collected by means of an anonymous questionnaire. The questionnaire focused on demographic data, previous research experience, current involvement in research and views on the value of research, obstacles to research, and proposed solutions to barriers to research. A total of 124 questionnaires were completed. To ensure fairness and minimise real or imagined repercussions for respondents, findings were not reported by training institution. Descriptive statistics were performed using MS Excel.

\section{Results}

Results are presented in Fig. 1 and Table 1.

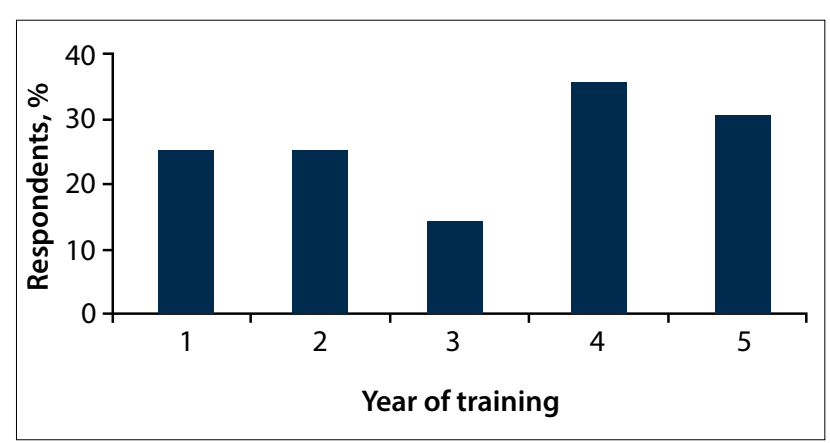

Fig. 1. Distribution of respondents. 


\section{Table 1. Descriptive statistics}

\begin{tabular}{|c|c|}
\hline University medical schools sampled, $N$ & 8 \\
\hline Registrars currently enrolled, $N$ & 241 \\
\hline Completed questionnaires, $n$ & 124 \\
\hline Registrars with no research experience, $n / N(\%)$ & $87 / 124(70.2)$ \\
\hline Registrars with research experience, $n / N(\%)$ & 37/124 (29.8) \\
\hline Undergraduate level, $n$ & 23 \\
\hline Postgraduate level, $n$ & 14 \\
\hline \multicolumn{2}{|l|}{$\begin{array}{l}\text { Registrars strongly agreeing or agreeing with the statements } \\
\text { below, } n / N(\%)\end{array}$} \\
\hline Their institution adequately prepared them for research & $41 / 124(33.1)$ \\
\hline They received formal research training & $52 / 124(41.9)\left(22-100^{\dagger}\right)$ \\
\hline They were aware of ongoing research in their department & 98/124 (79.0) \\
\hline They were currently involved in research (other than MMed) & $54 / 124(43.5)\left(0-79^{\dagger}\right)$ \\
\hline $\begin{array}{l}\text { They recognised the value of undertaking research, apart } \\
\text { from requirement for registration }\end{array}$ & $84 / 124(67.7)\left(44-89^{\dagger}\right)$ \\
\hline \multicolumn{2}{|l|}{ Agreed reasons for performing research ${ }^{*} n / N(\%)$} \\
\hline Advancement of knowledge & $52 / 124(41.9)$ \\
\hline Requirement for registration & $45 / 124(36.3)$ \\
\hline Academic promotion & $9 / 124(7.3)$ \\
\hline Fame & $5 / 124(4.0)$ \\
\hline Wealth & $5 / 124(4.0)$ \\
\hline \multicolumn{2}{|l|}{ Identified obstacles to research ${ }^{*}, n / N(\%)$} \\
\hline Insufficient time & $109 / 124(87.9)$ \\
\hline Inadequate of training in the research process & $40 / 124(32.3)$ \\
\hline Lack of supervisors & $31 / 124(25.0)$ \\
\hline Insufficient funding & $25 / 124(20.2)$ \\
\hline Lack of ongoing research within the department & $11 / 124(8.9)$ \\
\hline Other & $6 / 124(4.8)$ \\
\hline \multicolumn{2}{|l|}{ Proposed solutions $s^{*} n / N(\%)$} \\
\hline Dedicated research block & $116 / 124(93.5)\left(84-100^{\dagger}\right)$ \\
\hline Research methods course & $79 / 124(63.7)\left(27-100^{+}\right)$ \\
\hline $\begin{array}{l}\text { Supervision by faculty with MMed or higher postgraduate } \\
\text { degree }\end{array}$ & $73 / 124(58.9)\left(0-70^{\dagger}\right)$ \\
\hline More research exposure as undergraduates & $56 / 124(45.2)\left(0-68^{\dagger}\right)$ \\
\hline Other & $4 / 124(3.2)$ \\
\hline Registrars with plans to undertake future research, $n / N(\%)$ & $81 / 124(65.3)\left(33-78^{+}\right)$ \\
\hline
\end{tabular}

\section{Discussion}

Respondents identified lack of time, lack of supervisors and lack of training in research methodology as significant obstacles to research. They proposed a dedicated research block, formal training in research methodology, supervision of research by faculty with an MMed degree or higher, and greater undergraduate research exposure as solutions to the obstacles identified.

Owing to the high burden of disease, the relative shortage of trained surgeons and a
'Halstedian' approach to surgical training (in place for over a century, and encompassing exposure to graduated clinical experience in the operating room during several years of registrar training under the close tutelage of dedicated senior consultant surgeons), the surgical registrar in SA is arguably heavily overworked. Against this background, it is therefore not surprising that most of the respondents view lack of time as the major obstacle to completing their research projects.
Since consultant surgeons fluent in the nuances of research are most likely to ensure that the time registrars invest in research is productive, we suggest a supervisor's course in research methodology as a minimum requirement for all consultants responsible for supervising registrar research. Training institutions should provide consultants with incentives to upskill, obtain research degrees and increase their research output. Furthermore, there is a need to improve communication between registrars and departments on planned and ongoing research, to identify possibilities for registrar involvement.

Only a minority of the respondents agreed that their institution adequately prepared them for research. This finding mirrors those of the American Surgical Association's Blue Ribbon Committee on surgical education, which found that research training in the USA is thought to lack the structure, organisation and strict oversight that are well developed in clinical training. ${ }^{[2]}$

In order to improve the research capability of registrars, we suggest mandating the completion of a validated formal research methodology course for all surgical registrars within the first year of their registrar training, or as a requirement for qualification for the surgical intermediate examination. In addition, we suggest provision of time to be dedicated solely to research and the completion of a research project within the framework of existing surgical training programmes. The decrease in registrars' clinical responsibility during this time would necessitate the employment of additional registrars or medical officers in order to mitigate deficiencies in clinical service. We found that research exposure varied widely between training institutions, indicating a need to strengthen research training and output at certain institutions.

A minority of surgical registrars have previous research experience, although no significant differences in perceptions of research existed between the researchexperienced and research-naive groups. This similarity between the two groups is counterintuitive and, owing to the low number of respondents with previous research experience, may be a type II error. Furthermore, the finding is limited by the subjective perception of previous research experience. A limitation of this study that may also contribute to this finding is the failure to distinguish between respondents with previous research exposure as undergraduate medical students and those with previous research exposure as undergraduates in other fields. 
The majority of surgical registrars value completing a research project and plan to continue to undertake research in the future. This finding mirrors a study conducted among general surgeons in the UK, which found that general surgeons believed research training and undertaking research to be critical to surgical training and practice. ${ }^{[4]}$

Given the decrease in funding for academic hospitals over the past 20 years and the consequent drop in research output of SA medical institutions, ${ }^{[5]}$ the recently instituted research component of specialist training presents the opportunity to revive research and has substantially changed the training requirements of surgical registrars in SA. Training in research needs to be balanced with the provision of services in a resource-limited environment and the training of surgical specialists in the required core clinical competencies. ${ }^{[6]}$

\section{Conclusions}

Many challenges face surgical registrars and their efforts to undertake research. It is reassuring that registrars view research as an important component of their careers and are willing to propose solutions to the problems they encounter. Future enquiry may seek to capture the perceptions of academic surgical consultants with regard to research and their role in the training of registrars. SA has a history of producing medical breakthroughs. ${ }^{[7,8]}$ The now compulsory research project may reinvigorate the culture of surgical research and innovation, provided that the conditions suggested to facilitate this are implemented.

\section{References}

1. Health Professions Council of South Africa Subcommittee for Postgraduate Education and Training (Medical). New Requirements for the Registration of Specialists in South Africa http://www org.za/downloads/medical_dental/new_requirements_forregistration_of_specialists_in_sa.pdf (accessed 12 June 2015).

2. Debas HT, Bass BL, Brennan MF, et al. American Surgical Association Blue Ribbon Committee Report on Surgical Education 2004. Ann Surg 2005;241(1):1-8. [http://dx.doi.org/10.1097/01. Report on Surgical Ed

3. Reid K, Montgomery BD, Stocks NP, Farmer, EA. General practice research training: Impact of the Australian Registrar Research Workshop on research skills, confidence, interest and involvement of participants, 2002-2006. Fam Pract 2008;25(2):119-126. [http://dx.doi.org/10.1093/fampra/cmn010]

4. Dawson J, Harrison E, Taylor I. Research in the training of general surgeons: Results of a survey. Ann R Coll Surg Engl 1996;78(3):188-191.

Benatar SR. Health care reform in the new South Africa. N Engl J Med 1997;336(12):891-895. [http:// dx.doi.org/10.1056/NEJM199703203361224]

6. Krige JE. Departments of surgery in South Africa - legacies of the past, challenges for the future. S Afr J Surg 2004;42(3):76-77.

7. Barnard CN. The operation. A human cardiac transplant: An interim report of a successful operation performed at Groote Schuur Hospital, Cape Town. S Afr Med J 1967;41(48):1271-1274

8. Brenner S. Worms and science: An interview with Sydney Brenner, distinguished research professor at The Salk Institute, La Jolla, USA, and one of the winners of the 2002 Nobel Prize for Physiology and at The Salk Institute, La Jolla, USA, and one of the winners of the 2002 Nobel Prize for Physiology and
Medicine. EMBO Rep 2003;4(3):224-226. [http://dx.doi.org/10.1126/science.1088539, http://dx.doi. org/10.1126/science.302.5645.533, http://dx.doi.org/10.1126/science.301.5630.167c] 